\title{
ANALISIS PELAKSANAAN PRAKTIKUM MORFOLOGI TUMBUHAN MAHASISWA PENDIDIKAN BIOLOGI FKIP UMS TAHUN AJARAN 2017/2018
}

\author{
Lina Agustina ${ }^{1}$, Rivky Arif Rahmat ${ }^{1}$ \\ ${ }^{1}$ Prodi Pendidikan Biologi FKIP Universitas Muhammadiyah Surakarta \\ email:1a263@ums.ac.id
}

\begin{abstract}
The purpose of this research is to know the practical implementation of the morphology of the plant biology education students FKIP UMS 2017/2018 school year. This research is descriptive research with the research sample is a student semester 1 Biology education UMS, which travels the eyes of practical morphology of plants taken with Taro Yamane formula to get the number of samples in overall by as much as 81 students. Data collection techniques by using question form. The results of the analysis of the data shows that in practical plant morphology, 91\% of students familiar with plants/preparations are used, $53 \%$ of the students stated the time used in practical enough to complete the practical work, and from the a series of practical work each meeting there is a $65 \%$ of students who have difficulty in observing and drawing plant organs into practical report.
\end{abstract}

Key words: analysis, practical plant morphology

\begin{abstract}
Abstrak
Tujuan penelitian ini adalah untuk mengetahui pelaksanaan praktikum morfologi tumbuhan mahasiswa pendidikan Biologi FKIP UMS tahun ajaran 2017/2018. Penelitian ini merupakan penelitian deskriptif dengan sampel penelitian adalah mahasiswa semester 1 pendidikan Biologi UMS yang menempuh mata praktikum morfologi tumbuhan yang diambil dengan rumus Taro Yamane hingga mendapatkan jumlah sampel secara keseluruhan sebanyak 81 mahasiswa. Teknik pengumpulan data dengan menggunakan angket. Hasil analisis data menunjukkan bahwa dalam praktikum morfologi tumbuhan, $91 \%$ mahasiswa familiar dengan tanaman/ preparat yang digunakan, 53\% mahasiswa menyatakan waktu yang digunakan dalam praktikum cukup untuk menyelesaikan praktikum, dan dari serangkaian praktikum setiap pertemuan terdapat $65 \%$ mahasiswa yang kesulitan dalam mengamati dan menggambar organ tanaman ke dalam laporan praktikum.
\end{abstract}

Kata kunci: analisis, praktikum morfologi tumbuhan

\section{PENDAHULUAN}

Pendidikan diartikan sebagai sebuah proses dengan metode - metode tertentu sehingga orang memperoleh pengetahuan, pemahaman, dan cara bertingkah laku yang sesuai dengan kebutuhan. Kemampuan dan keterampilan yang dimiliki seseorang tentu sesuai dengan tingkat pendidikan yang diikutinya, semakin tinggi pendidikan seseorang maka semakin tinggi pengetahuan, keterampilan dan kemampuan (Sagala, 2010). Hal ini menunjukkan bahwa melalui pendidikan, kesejahteraan seseorang dapat meningkat sesuai dengan tingkat pendidikan yang mereka lampaui. Dengan demikian dapat ditegaskan bahwa fungsi pendidikan adalah membimbing siswa/mahasiswa ke arah suatu tujuan yang kita nilai tinggi dan pendidikan yang baik adalah usaha yang berhasil membawa semua siswa/mahasiswa kepada tujuan tersebut. 
Dalam dunia pendidikan, salah satu mata pelajaran yang ditempuh mulai dari tingkat dasar sampai menengah adalah biologi, biologi merupakan mata pelajaran yang termasuk dalam rumpun ilmu pengetahuan alam (IPA/sains). Ilmu sains berkaitan dengan cara mencari tahu (inquiry) tentang alam secara sistematis, sehingga pembelajaran bukan hanya sebagai penguasaan kumpulan yang berupa fakta-fakta, konsep-konsep saja, tetapi juga merupakan suatu proses penemuan. Oleh karena itu, pembelajaran biologi menekankan pada pemberian pengalaman langsung bagi siswa untuk mengembangkan kompetensi dan mengarahkan mereka untuk mencari tahu dan untuk memperoleh pemahaman yang lebih mendalam tentang dirinya sendiri dan alam sekitar. Salah satu cara untuk membelajarkan materi biologi adalah dengan praktikum, karena di dalam praktikum siswa/mahasiswa dapat menemukan sendiri dan mendapatkan pemahaman yang lebih tentang materi yang sedang dipelajari.

Menurut Hastuti (2013), pembelajaran biologi tidak hanya dilakukan di dalam kelas. Ciri dari pembelajatan biologi adalah adanya kegiatan praktikum baik di dalam laboratorium mauun di alam. Banyak konsep biologi yang kompleks sehingga diperlukan suatu kegiatan untuk memudahkan siswa dalam memahami konsep tersebut.

Salah satu program studi yang terdapat pada FKIP Universitas Muhammadiyah Surakarta adalah program studi pendidikan biologi. Proses pembelajaran di prodi Biologi selain di dalam kelas juga terdapat praktikum yang ditempuh mahasiswa mulai dari semester 1 sampai semester 8. Salah satu mata praktikum dalam program studi pendidikan Biologi FKIP UMS adalah Praktikum Morfologi Tumbuhan, dalam praktikum ini mempelajari tentang morfologi tumbuhan dimulai dari daun tunggal, daun majemuk, tata letak daun pada batang, bunga tunggal, bunga majemuk, pembuatan herbarium dan katalog organ pada tumbuhan.

Praktikum morfologi tumbuhan ditempuh oleh mahasiswa semester 1, dimana sebagian dari mahasiswa belum berpengalaman pada kegiatan praktikum, hal ini dikarenakan sebagian dari mahasiswa jarang melakukan praktikum ketika berada di sekolah menengah dan untuk materi morfologi tumbuhan sendiri di SMP dan SMA hanya diajarkan sedikit sehingga pengetahuan tentang morfologi tumbuhan kurang maksimal. Oleh karena itu penelitian tentang "Analisis Pelaksanaan Praktikum Morfologi Tumbuhan mahasiswa Pendidikan Biologi FKIP UMS pada tahun ajaran 2017/2018” penting untuk dilakukan.

\section{METODE PENELITIAN}

Penelitian ini menggunakan pendekatan kualitatif dimana dalam penelitian ini lebih menekankan pada makna dan proses daripada hasil suatu aktivitas. Jenis penelitian deskriptif kualitatif yang digunakan pada penelitian ini dimaksudkan untuk memperoleh informasi mengenai pelaksanaan praktikum morfologi tumbuhan pada tahun ajaran 2017/2018. Selain itu, dengan pendekatan kualitatif diharapkan dapat diungkapkan situasi dan permasalahan yang dihadapi mahasiswa ketika pelaksanaan kegiatan praktikum morfologi tumbuhan. Penelitian ini Laboratorimum Biologi, FKIP, UMS. Penelitian dilaksanakan pada bulan september sampai desember 2017. Populasi terdiri dari semua mahasiswa yang mengambil mata praktimum morfologi tumbuhan (103 mahasiswa) dan pengambilan sampel dengan menggunakan rumus Taro Yamane:

Keterangan:

$$
\mathrm{N}=\frac{N}{N . d 2+1}
$$

$$
\mathrm{n}=\text { jumlah sampel }
$$


$\mathrm{N}=$ jumlah populasi

$\mathrm{d}^{2}=$ presisi yang ditetapkan $0,05(5 \%)$

Berdasarkan rumus di atas diperoleh sampel sebanyak 81 mahasiswa.

Teknik pengumpulan data pada penelitian ini adalah menggunakan angket yang diisi oleh mahasiswa setelah menempuh seluruh kegiatan praktikum morfologi tumbuhan, dimana ada 6 latihan dalam praktikum morfologi tumbuhan. Dengan tujuan untuk mendapatkan data tentang pelaksanaan praktikum.

Analisis data dilakukan dengan menganalisis angket yang telah diisi mahasiwa dengan cara: a) mengumpulkan data ari angket; b) mengklasifikasikan alternatif jawaban responden; 3) menentukan besar presentase alternatif jawaban responden.

\section{HASIL DAN PEMBAHASAN \\ Deskripsi Data}

Hasil penelitian tentang pelaksanaan praktikum morfologi tumbuhan pada mahasiswa pendidikan biologi, FKIP UMS pada setiap indikator terdapat pada tabel di bawah ini:

Tabel 1. Pelaksanaan Praktikum Morfologi Tumbuhan

\begin{tabular}{|c|cl|c|}
\hline \multicolumn{2}{|c|}{ Indikator } & Persentase \\
\hline 1 & & Preparat yang digunakan & \\
& a & Familiar & $91 \%$ \\
& b & Kurang familiar & $9 \%$ \\
\hline 2 & & Kesesuaian dengan materi kuliah & \\
& a & Sesuai & $100 \%$ \\
& b & Tidak sesuai & $0 \%$ \\
\hline 3 & & Waktu pelaksanaan praktikum & \\
& a & Selesai tepat waktu & $53 \%$ \\
& b & Tidak selesai tepat waktu & $47 \%$ \\
\hline 4 & & Asisten prakikum & $87 \%$ \\
& a & Menguasai materi & $13 \%$ \\
& b & Kurang menguasai materi & $65,4 \%$ \\
\hline 5 & \multicolumn{2}{|l|}{ Kesulitan dalam praktikum } & $22,2 \%$ \\
& a & Menggambar organ tumbuhan & $12,4 \%$ \\
& b & Membuat deskripsi tumbuhan & \\
& c & Menjawab soal diskusi & \\
\hline
\end{tabular}

\section{PEMBAHASAN}

\section{Preparat yang digunakan}

Berdasarkan tabel 1, dapat diketahui bahwa pada indikator pertama yaitu preparat yang digunakan sebanyak $91 \%$ menjawab familiar dengan preparat yang digunakan dan $9 \%$ menjawab tidak familiar. Preparat yang digunakan diambil dari sekitar daerah Surakarta yang seharusnya cukup dikenal oleh mahasiswa sehingga tidak kesulitan untuk mengidentifikasi bagian dari tanaman yang digunakan. Preparat yang digunakan meliputi daun, batang dan bunga. Preparat merupakan bahan utama yang disediakan pada saat tahap persiapan, bersamaan dengan menyiapkan alat. Hal ini sejalan dengan penelitian Hamidah (2014), yang menyatakan bahwa persiapan sarana dan prasarana merupakan hal yang penting dalam mendukung terlaksananya kegiatan praktikum.

\section{Kesesuaian Materi Kuliah dengan Materi Praktikum}


Pada indikator kedua yaitu kesesuaian antara materi kuliah dengan materi praktikum, $100 \%$ mahasiswa menjawab sesuai, karena dasar dari kegiatan praktikum adalah rencana pelaksanaan praktikum yang dibuat selaras dengan rencana materi perkuliahan yang sama yaitu morfologi tumbuhan. Hal ini sesuai dengan penelitian Agustina (2016), yang menyatakan bahwa tingkat kesesuaian materi kuliah dengan materi praktikum biologi bidang tumbuhan program studi Pendidikan Biologi termasuk dalam kategori "sangat sesuai" dan "sesuai", sehingga mahasiswa lebih mudah untuk memahami materi di kelas karena didukung oleh kegiatan praktikum

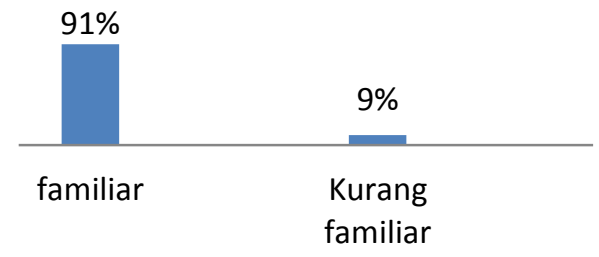

\section{Gambar 1. Persentase pemahaman mahasiswa terhadap Preparat yang digunakan}

\section{Kesesuaian Materi Kuliah dengan Materi Praktikum}

Pada indikator kedua yaitu kesesuaian antara materi kuliah dengan materi praktikum, 100\% mahasiswa menjawab sesuai, karena dasar dari kegiatan praktikum adalah rencana pelaksanaan praktikum yang dibuat selaras dengan rencana materi perkuliahan yang sama yaitu morfologi tumbuhan. Hal ini sesuai dengan penelitian Agustina (2016), yang menyatakan bahwa tingkat kesesuaian materi kuliah dengan materi praktikum biologi bidang tumbuhan program studi Pendidikan Biologi termasuk dalam kategori "sangat sesuai" dan "sesuai", sehingga mahasiswa lebih mudah untuk memahami materi di kelas karena didukung oleh kegiatan praktikum

\section{Waktu Pelaksanaan Praktikum}

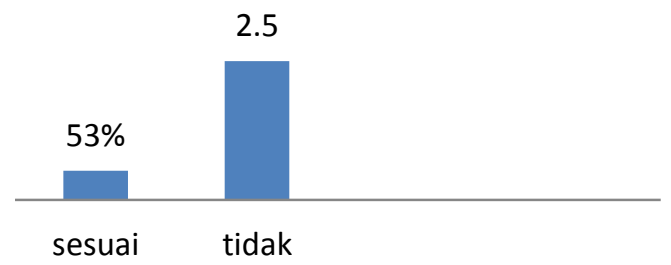

\section{Gambar 2. Waktu pelaksanaan praktikum}

Pada indikator ketiga yaitu waktu pelaksanaan praktikum. 53\% mahasiswa mampu menyelesaikan praktikum tepat waktu sesuai jadwal yang telah ditentukan dan $47 \%$ mahasiswa tidak tepat waktu sehingga ketika waktu selesai mereka belum menyelesaikan seluruh laporan praktikum pada hari tersebut. Hal ini sejalan dengan penelitian Mariyam (2015), yang menyatakan bahwa 69\% siswa telah melaksanakan praktikum tepat waktu yang artinya mereka sudah bisa bersikap disiplin waktu serta dapat memahani jika harus menyiapkan segala sesuatu terlebih dahulu sebelum praktikum dilaksanakan.

\section{Peran Asisten Praktikum}




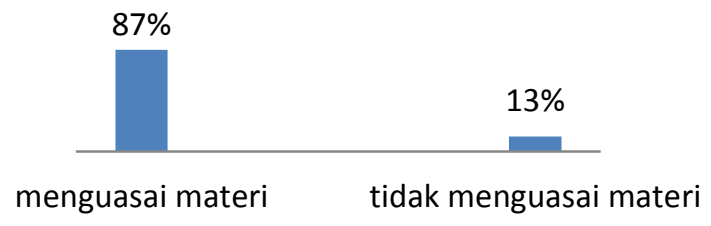

\section{Gambar 3. Persentase penguasaan materi asisten Laboratorium dalam pendampingan}

Pada indikator keempat yaitu peran asisten praktikum ketika kegiatan praktikum, ada $87 \%$ mahasiswa yang menyatakan bahwa peran asisten sangat penting karena asisten akan membantu mahasiswa ketika mereka kesulitan tanpa langsung bertanya kepada dosen pengampu, sehingga asisten menguasai materi praktikum. Sedangkan 13\% mahasiswa menyatakan bahwa asisten kurang menguasai materi praktikum. Sejalan dengan penelitian Wahyudiati (2016) bahwa pada saat pelaksanaan praktikum asisten laboratorium (Coass) membantu dalam kegiatan praktikum walaupun harus itingkatkan koordiansi antara laboran, coass dan dosen pengampu.

\section{Kesulitan dalam Pelaksanaan Praktikum}

Pada indikator kelima yaitu kesulitan dalam praktikum, dimana terdapat beberapa tahapan yang dianggap sulit oleh mahasiswa ketika praktikum yaitu kegiatan mengamati organ tumbuhan dan menggambarkannya ke dalam laporan, terdapat $65,4 \%$ mahasiswa yang kesulitan. Presentase kesulitan pada tahapan mengerjakan deskripsi organ tumbuhan sebanyak 22,2\% dan presentase kesulitan dalam menjawab soal diskusi sebanyak $12,4 \%$. Hal ini menunjukkan mahasiswa belum siap untuk kegiatan pengamatan, karena pada mata praktikum morfologi tumbuhan kegiatan paling domina adalah pengamatan bagian atau organ dari tumbuhan. Mahasiswa msih mengalami kesulitan dan idetifikasi ciri tumbuhan secara morfologi.

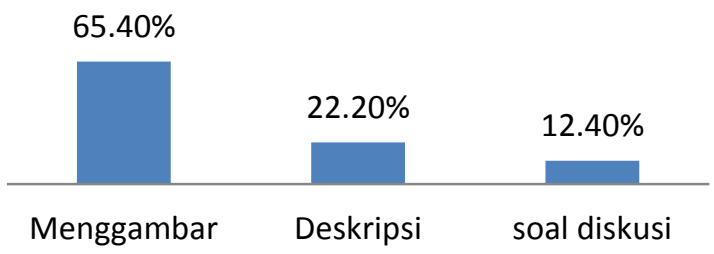

\section{Gambar 4. Persentase Kesulitan dalam Pelaksanaan Praktikum}

\section{KESIMPULAN}

Berdasarkan data dan hasil analisis, maka dapat ditarik kesimpulan bahwa kegiatan praktikum morfologi tumbuhan sudah berjalan dengan baik, tetapi perlu diperhatikan kembali berapa jumlah preparat yang digunakan agar mahasiswa tepat waktu dalam mengerjakannya, dan perlu pembimbingan tambahan agar mahasiswa tidak kesulitan dalam mengidentifikasi tanaman.

\section{DAFTAR PUSTAKA}

Agustina, E. 2016. "Analisis Kesesuaian Materi Kuliah Dengan Materi Praktikum Biologi Bidang Tumbuhan Pada Program Studi Pendidikan Biologi UIN ArRaniry". Jurnal Biotik. Vol 4. No 2. Hal: 156-162. 
Hamidah, A., Sari, E. N., \& Budianingsih, R. S. 2014. "Persepsi Siswa Tentang Kegiatan Praktikum Biologi di Laboratorium SMA Negeri Se-Kota Jambi. Jurnal Sainmatika. Vol 7 No 1. Hal: 81.

Hastuti, A. 2013. "Penerapan Pembelajaran Berbasis Praktikum untuk Meningkatkan Motivasi dan Hasil Belajar Biologi Materi Pokok Sistem Reproduksi Manusia". Skripsi: Yogyakarta: Jurusan Pendidikan Biologi Fakultas Sainstek UIN Sunan Kalijaga.

Mariyam, S. 2015. "Analisis Pelaksanaan Praktikum Pada Pembelajaran Siswa Kelas VII SMP Negeri 3 Kunto Darussalam Tahun pelajaran 2014/2015”. e-jurnal mahasiwa prodi biologi. Vol 1. No 1.

Sagala, S. 2009. Konsep Dan Makna Pembelajaran. Bandung: Alfabeta. Hal: 3

Wahyudiati. D. 2016. "Analisis Efektivitas Kegiatan Praktikum Sebagai Upaya Peningkatan Hasil Belajar Mahasiswa". Jurnal Tatsqif. Vol 14. No 2. Hal: 143-168. 